\title{
Moving forward with early childhood care and education (ECCE) post-2015 in the Asia Pacific Region: an analysis of global and national policy goals
}

\author{
Emma C. Pearson * (1)
}

\section{*Correspondence:} emmapearson@gmail.com School of Social Sciences, Bishop Grosseteste University, Lincoln, UK

\begin{abstract}
This paper presents a thematic analysis of documents produced during a recent 'Regional Policy Forum on Early Childhood Care and Education (ECCE)', attended by over 200 participants including representatives from key international donor organisations and high-level officials from over 30 countries across the Asia Pacific region. The paper begins by providing a brief overview of international developments in ECCE over the past two decades, highlighting a growing argument that points to the need for a shift in policy and programming agendas away from target setting at international levels, towards the promotion and support of localized, contextually grounded approaches to supporting policies and programmes in ECCE. In an attempt to find ways of establishing empirical support for this argument, the paper explores the extent to which key messages delivered by international donor organizations and representatives at the Policy Forum can be seen to reflect the current activities and concerns of countries within the region (as expressed through individual country reports presented during the forum). Based on results of this analysis, the paper concludes with recommendations for balancing the 'local' and 'international' influence on policy making and agenda setting as countries in the Asia Pacific region move forward with provision of formalized ECCE post-2015.
\end{abstract}

Keywords: Early childhood, Policy, Thematic analysis, Asia Pacific, Millennium Development Goals, Post-2015

\section{Background}

During the past two decades, the global field of early childhood care and education (ECCE) has been heavily influenced (and impelled) by key human development targets outlined in the millennium development goals (MDGs) and education for all (EFA). In particular, Goal 1 of EFA (Expanding and improving comprehensive early childhood care and education, especially for the most vulnerable and disadvantaged children) has triggered rapid growth in formalized programming and policy making in the global field of early childhood. The impetus provided by EFA and the MDGs has contributed significantly to raising awareness that early experiences shape subsequent development, to

(c) 2015 Pearson. This article is distributed under the terms of the Creative Commons Attribution 4.0 International License (http:// creativecommons.org/licenses/by/4.0/), which permits unrestricted use, distribution, and reproduction in any medium, provided you give appropriate credit to the original author(s) and the source, provide a link to the Creative Commons license, and indicate if changes were made. 
enhancing the profile of early childhood as a field of research, policy and practice, and to initiating important programmes designed to improve the health and well-being of millions of children. Driven significantly by commitments to EFA and the MDGs, a majority of countries within the Asia Pacific region (which, based on participation in the Regional Policy Forum that is documented for the purposes of this paper, includes South Asia, East Asia, South East Asia, the Pacific Islands, Australia and New Zealand) have implemented, or are in the process of approving, national policies geared towards the care and education of young children.

As the background papers and policy reviews informing the Regional Policy Forum point out (http://unesdoc.unesco.org/images/0022/002253/225312e.pdf), government investment in early childhood care and education for many countries within the Asia Pacific region is severely limited. In these countries, provision of early learning and care services tends to be heavily reliant on funding and support from international donor agencies, most of whom also play an important advocacy role in their work with government departments. As a result, national policy on early childhood care and education often reflects a focus on the achievement of international development goals (outlined, for example, in the MDGs and EFA) that guide much of the work of international donor agencies. Concerns associated with this tendency were raised by UNESCO in the 2005 Global Monitoring Report on EFA, titled 'Education for All: The quality imperative' (UNESCO 2004), which highlighted that the rapid global pursuit of universalising access to education and increasing enrolment rates (a key target of EFA) was jeopardizing quality provision in many countries.

As the 2015 'deadline' for MDG and EFA targets approaches, there are indications that a change in policy focus is now needed to achieve greater balance between the influence of 'local', national priorities, circumstances and needs against international goals. Recent reviews of developments in ECCE within the Asia Pacific region have argued that greater balance between (1) the goals and targets of international donor organisations who provide significant support for provision of ECCE in many countries and (2) country-specific circumstances, priorities and needs, would benefit efforts to enhance formalized provision of early childhood care and education (Pearson and Tan 2013). More specifically, as Koehler et al. (2012, p. 8) have suggested, there is now a need for 'policy space (to) be opened up, empowering individual countries to formulate and adopt strategies that move beyond the conventional and that match their own circumstances'.

This paper responds to the concerns outlined above by attempting to establish empirical support to highlight (1) current areas of difference and similarity between international' and 'national' goals and concerns and (2) possibilities for the 'opening up of space' for national policies to be influenced more significantly by their own country's unique needs, capacities and priorities. By way of a theoretical framework, the paper draws on Harkness and Super's (2010) conceptualization of policies as 'cultural products' to explore, first, whether countries within the region do appear to have specific and unique policy-related concerns and subsequently, ways in which these might be more clearly reflected in the international goals and priorities that underpin much of the current rationale for donor funding.

This argument is also supported by a literature base that highlights the importance of contextual factors in shaping both policy and program implementation. There is 
widespread acceptance within the field of ECCE that effective strategies to impact positively and effectively on the lives of young children living across widely diverse contexts, must address a complex interplay of contextually determined influences across government and non-government agencies; professional organisations and institutions and, perhaps most importantly, communities and families (Rebello Britto et al. 2013a). Again, the 2007 EFA Global Monitoring Report on early childhood acknowledged this, highlighting the importance of contextually grounded approaches to providing ECCE as follows: ' $(T)$ here is no universal model of early childhood provision that can be followed globally. Each nation has to determine its own way forward' (UNESCO 2006, p. 154). Indeed, an array of evidence from various disciplines (Penn 2011 Ryan and Cousins 2009; Myers 2006; Woodhead 1999; Fullan and Hargreaves 1992) suggests that when policies or initiatives do not sufficiently match the underlying values and priorities of the people or communities they are designed to serve, their success is questionable from the outset. Within the field of ECCE, examples of policies that have in fact restricted, rather than facilitating, developments in young children's learning and development, highlight the extent to which externally imposed perspectives, or measures, can exert a negative impact on early childhood programmes. Evans (1995), for example, highlights examples from Nigeria, where impractical regulations based on standards from developed countries were imposed on local ECCE programmes, resulting in non-compliance and, thus, illegal practices. Relatedly, more recent research conducted within the Asian region has demonstrated the importance of 'grass roots' approaches in overcoming unique cultural and social challenges, such as gender inequity, in early schooling (Kirk and Winthrop 2006).

Harkness and Super (2010, p. 1) have suggested that 'policies are cultural products'. Others have also argued that national policies oriented towards children can be seen to reflect a country's past, present and future perspectives on children and childhood (Vergara del Solar 2014). While many professionals and practitioners involved 'on the ground' in ECCE tend to view policy making as a distant process driven by factors beyond their control, contemporary perspectives suggest that to effectively benefit young children, policies should be informed by knowledge about local circumstances, needs and priorities (Rebello Britto et al. 2008). The importance of contextual knowledge in policy making, however, presents a significant challenge for many countries across the world (and more specifically for the purposes of this paper within the Asia Pacific region) not only because of the tendency for international goals and targets to dominate policy and programming discussions and agendas, but also because information about 'local', national priorities, activities and needs in ECCE is not widely documented and/or disseminated (Chartier and Geneix 2006). Given this gap, it is perhaps not surprising that ECCE policies in many countries within the region have tended to be weighted towards international discourse on early learning and development (such as 'school readiness', as reflected in the Regional Policy Forum agenda outlined in this paper), informed heavily by an evidence base emanating largely from Westernised contexts; or that implementation of these policies in many countries has been slow and difficult (Pearson and Tan 2013). 


\section{Exploring possibilities for policy making post-2015}

As highlighted above, impetus from the MDGs and EFA has resulted in a burgeoning of policy and programming for provision of formalized ECCE across the Asia Pacific region. This, in turn, has raised awareness across the region about the importance of intervening to ensure healthy development and learning in the years prior to entry into formal schooling (reflected, for example, in increased enrolment in ECCE across the region, Rao and Jin 2010). Implementation of formalized ECCE across the diverse regions and communities of the Asia Pacific region has also generated awareness not only of the benefits, but also the challenges associated with working towards universal enrolment (Rao and Jin 2010). As evidenced in the information presented in this paper, individual countries have, as part of this process, identified important, unique issues that play an important role in shaping the implementation of ECCE policies and programmes in their own context. All these factors indicate that there may, indeed, now be opportunities for increasing the space for individual countries to formulate policies that 'speak to' the unique contexts in which their children are being raised, balancing the influence of 'international' and 'national' goals in policies that aim to support provision of ECCE post-2015.

This paper seeks to provide evidence for the argument outlined above, by making use of outputs (documents) produced from a recent (2013) regional early childhood Policy Forum, in which over 200 individuals, including ministerial-level delegates from countries across the Asia Pacific region, participated (the full set of documents produced during the forum can be found at http://www.unescobkk.org/education/ecce/what-we-do/ policy-research-advocacy/). Thematic analysis of the documents is conducted to explore key concerns, messages and priorities outlined in presentations delivered by, or on behalf of (1) international donor organisations operating within the region and regional-level early childhood networks working closely with these organisations, and (2) individual countries located within the region. The rationale behind the approach taken in this set of analyses is that, as Lincoln and Guba (1985) have suggested, documents can provide a useful source of qualitative data, as they are usually grounded in specific contexts and can, therefore, be seen to provide important situational insights.

While this 'dataset' is limited in various terms (including, for example, the pre-determined nature of agendas and presentations set by the host organisations, as well as limitations regarding the extent to which countries' current policies as a whole can be seen to be represented in the documents produced by the Forum), it is nonetheless valuable in that it contains up-to-date information that may be seen to reflect current international donor agendas as well as country-based initiatives in/priorities for early childhood care and education across the Asia Pacific region.

\section{Methods}

The choice of methodology for this 'study' was influenced strongly by the nature of the Regional Policy Forum, and a desire on the part of the author to acknowledge this as a key factor in both contributing to and shaping the findings reported here. As one of the principal conveners of the Forum, the United Nations Educational, Scientific and Cultural Organizations (UNESCO, Bangkok office) gives public access to all reports, presentations and papers delivered during the course of the Forum via its webpage (http:// 
www.unescobkk.org/education/ecce/what-we-do/policy-research-advocacy/presentations/). As the Policy Forum brought together a large number of participants (including country delegations led by high-level government officials, representatives of UN agencies, research institutes and networks) from 31 countries, these outputs provide a highly important, rich, easily accessible source of information about current ECCE agendas and activities across the Asia Pacific region. For the particular purposes of this paper, the Forum documents provide an ideal dataset for analysis because they are explicitly organized around two key participant groups: one group representing international and regional perspectives/expertise (consisting of international and regional experts in the field, along with senior officials from the host organizations), and a second group presenting country-based perspectives and insights (consisting of government officials and representatives from each of the participating countries). Since the purpose of this paper is to explore the possibility that opportunities do exist for creating more 'space' in policy-related discussions at regional and international levels for consideration of more localized concerns among individual nations (as suggested by Koehler et al. 2012), the dataset provides a valuable opportunity for analysis. Further details on the documents provided on the UNESCO website and downloaded for analysis are provided in Table 1.

Table 1 Details on full dataset of documents produced from regional forum/analyzed (documents available for download at http://www.unescobkk.org/education/ecce/whatwe-do/policy-research-advocacy/)

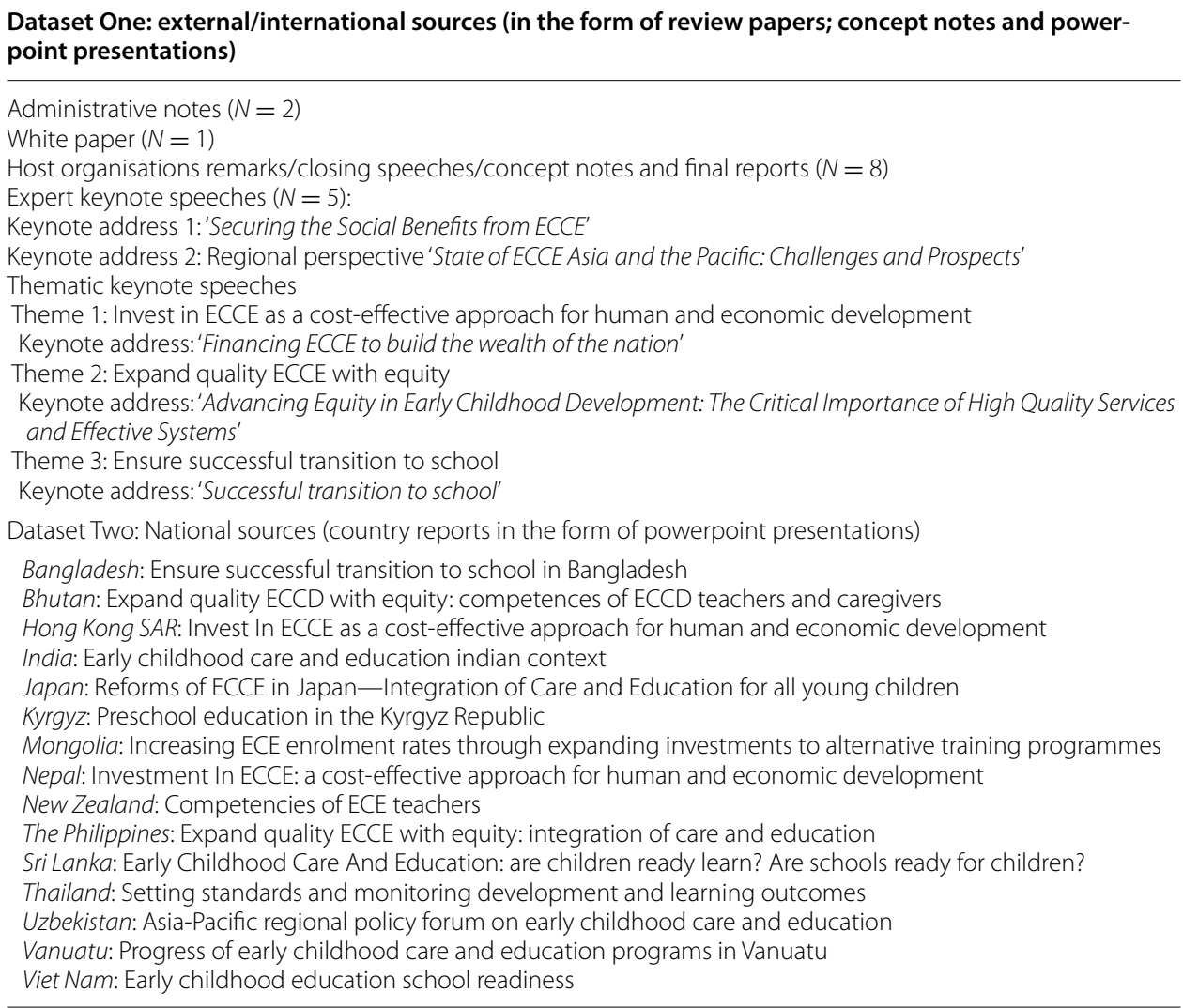


Notwithstanding the value of this dataset, it is important to acknowledge that the information available is inevitably shaped by the explicit agenda of the Policy Forum, as outlined in background documents (UNESCO 2013, p. 4):

1. 'Review the regions' ECCE situation, focusing on 3- to 5-year-olds and their successful transition into primary education, analyzing current status, gaps and emerging challenges and opportunities.

2. Showcase innovative ECCE initiatives for disadvantaged groups, which are costeffective, scalable and sustainable.

3. Identify the Asia Pacific region's priorities and strategies for the provision of quality ECCE, particularly for the most disadvantaged groups.

According to the same Report, part of the rationale behind the forum was '..an urgent need to accelerate the region's quantitative and qualitative progress toward EFA Goal 1 and to renew the countries' commitment to inclusive and holistic development and learning of children' (p. 6).

Therefore, the documents analyzed for the purposes of this paper cannot be seen to necessarily represent personal perspectives of authors/presenters. Rather, the focus in this analysis is on identifying themes that are common across participant presentations and papers within each of the two groups of interest, to examine elements of similarity and difference across broad 'international/regional' and 'national' priorities and agendas.

Thematic analysis was used for exploration of this particular dataset because it offers a more theoretically flexible approach to identifying patterns within qualitative data sets than other approaches, such as Interpretive Phenomenological Analysis (IPA); narrative analysis or grounded theory approaches (Braun and Clarke 2006). It is, therefore, more amenable to diverse datasets and purposes, and not restricted by a specific theoretical framework. As Braun and Clarke point out, despite (or because of) its flexibility, users of thematic analysis must, however, be transparent about their epistemological approach. The analyses presented here were guided by a specific 'question'/intention: to explore (1) the extent to which presentations/papers delivered by each of the two groups participating in the Forum could be seen to express a central set of policy-related concerns (as representative of both 'international/regional' and 'national' perspectives), and (2) possibilities for harmonization across the two (thereby addressing the central question of whether there are opportunities for opening up space to strengthen the influence of national circumstances and priorities in shaping ECCE policy). The analyses were designed to respond to/examine a particular set of concerns regarding a possible gap between 'international' development goals and 'national' circumstances/priorities as outlined by Koehler et al. (2012) and Fukuda-Parr (2012). While identification of particular sets of messages within each dataset was not intentional, it is important to acknowledge that the process of analysis may have been influenced by 'sensitizing concepts' encountered in building a rationale for these analyses. Hammersley (2006) describes sensitizing concepts as providing reference points for analysis of empirical instances. In this case, current discussions around the role of international goals in imposing particular influences on national policy and programming had been reviewed in preparation for the analysis. While this is normal practice in the research process, in the case of thematic 
analysis as Braun and Clarke (2006) suggest, articulation of possible theoretical influences is critical particularly because, as these authors suggest, this is a more important gauge of validity than inter-rater reliability or multiple-coder checking in the process of theme identification (http://www.psych.auckland.ac.nz/en/about/our-research/ research-groups/thematic-analysis/frequently-asked-questions-8.html\#c83c77d6d1c62 $5135085 \mathrm{e} 489 \mathrm{bd} 66 \mathrm{e} 765)$. In the process of identifying themes, the analyses were, therefore, underpinned by a mix of essentialist (representing concrete realities) and constructivist (seeking to examine the role of discourses in shaping these realities) methods. This mixed approach is referred to by Braun and Clarke (2006) as a 'contextualist' approach.

All documents (total 31) published online following completion of the Policy Forum were downloaded for analysis. The dataset was split into two parts, reflecting both the purposes of these analyses and the organization and presentation of documents on the dedicated Forum website (http://www.unescobkk.org/education/ecce/what-we-do/policy-research-advocacy/presentations/): 'Dataset One' ( $N=16$ documents), consisting of 'official welcoming remarks', 'closing comments' and 'keynote speeches' delivered by the host donor organisations and external experts (selected and commissioned by the host organisations), in three key aspects of early childhood care and education predefined by donor hosts and organisations as areas of policy interest. 'Dataset Two' ( $N=15$ documents) consisting of notes from presentations delivered by fifteen countries during the course of the forum. These presentations provided insights into current activities and areas of concern for each country. While Dataset One consists of a combination of written papers, speeches and powerpoint presentations, Dataset Two consists solely of powerpoint presentations.

Six steps recommended by Braun and Clarke (2006) as important for establishing rigor in thematic analysis were followed in the process of identifying the themes reported here. The two sets of data (as outlined above) were analyzed separately, following these procedures: initial familiarization with content across all documents; generation of initial codes (categories and/or keywords); generation of initial themes; review of themes using constant comparison; defining and naming themes, and organization/presentation of themes.

Initial familiarization involved downloading the whole dataset, organizing available presentations/papers into the two groups and careful checking to assess the extent to which these two groups could be seen as distinct and reflecting both international/ regional' and 'national' perspectives. The presentations/papers delivered by participants within the first group (Dataset One) were distinctive in that they tended to consist largely of generic messages related to the importance of ECCE and expert inputs related to the three themes of the Forum, in contrast with those delivered by individual countries (Dataset Two), which were focused on context, concerns and activities within ECCE in individual countries. While the content of presentations/papers within each dataset could be seen to reflect the key messages/agendas underpinning the Forum, there were other clearly discernible and unique messages/'pockets of information' running across each dataset. For example, in the case of Dataset One, the importance of 'investment in young children', 'public funding' or 'economic return' on investment in ECCE was mentioned in all but two of the presentations/papers, regardless of the session or specific Forum theme in which the presentations/paper was delivered. Codes and 
categories were noted to reflect the pockets of information that characterized key messages within each dataset.

Once themes had been articulated and refined within each dataset, a process of crosschecking was carried out. For example, in the case of Dataset Two, information related to population data was compared against statistics available online to gain further insights, and policy reviews/reports from countries that presented, where accessible, were also accessed and reviewed as a means of cross-checking categories and themes that were identified.

The findings reported in this paper were presented at an international conference (the Comparative and International Education Society Conference), where useful feedback and affirmation were received. As further means of verification, a draft version of the paper was shared with a member of the Forum Organizing Committee for information and feedback.

\section{Results and discussion}

Through the six-step process outlined briefly above (Braun and Clarke 2006), three key themes were identified within each dataset. These themes are of note in that they cross (and are distinct from) the various specific topics of focus around which the Forum was organized. For example, within Dataset One (assumed to represent 'international', or 'regional' perspectives), three key sets of messages were found across the majority of presentations and Forum notes: Promotion of ECCE as a 'cure all'; Emphasis on Funding/ Financing of ECCE, and Repetition of Key Agendas. Three distinct themes also characterized Dataset Two (assumed to reflect 'national', or more localized, priorities and perspectives): Evidence of Diversity; Importance of Engagement Across Multiple Stakeholder Groups, and Gaps and Challenges. Each theme is described below and defined, with reference to illustrative excerpts taken from each Dataset.

\section{Dataset One: international and regional perspectives Theme One: promotion of ECCE as 'cure all'}

A strong recurring theme across all the various sources that form part of Dataset One was the repeated reference to 'compelling evidence' of the benefits of investing in young children's well-being. Within the overall theme of 'ECCE as a cure all', three sub-sets of messages were identified. One set of messages reflected a focus on the compelling 'evidence' that exists, in terms of the significance of development and learning during the early years of life; a second sub-set consisted of messages relating to the importance of ECCE in contributing to broader, societal health and well-being, and a third set emphasizing the importance of ECCE as a foundation for lifelong development and learning. Excerpts from Dataset One, organized here into the three sub-themes, provide some illustrations of how these messages were circulated in this policy forum:

Compelling evidence 'Participation in quality ECCE programmes is a strong predictor of academic achievement as well as improved social, economic and health outcomes'

'.. scientific studies confirm that early life experiences are built into our bodies and that prolonged adversity in early childhood can result in toxic stress and lifelong impairments in learning, health and behavior' 
'first 5 years lay foundations for language, academic abilities, habits and socio-emotional development'

Builds health and wealth of nations (productivity, school success, crime, unemployment) '..is indeed one of the best returns on our investment'

'Should nations wish to achieve equitable socio-economic progress and sustainable development, ECD cannot afford to be omitted or neglected'

'.. (quality of) ECCE..is essential for reaching learning goals'

Foundation of lifelong learning 'ECCE is the foundation of lifelong learning'

'ECCE policy also has the potential to decrease social inequalities'

'Social benefits include significant productivity of the society's workforce'

'Early life experiences are built into our bodies.... Prolonged adversity in early childhood can result in toxic stress and lifelong impairments in learning, health and behaviour'

'Brain circuitry is formed rapidly during early childhood'

The tendency for international organisations to present and promote evidence of ECCE as a panacea for social and economic challenges, to compel governments to invest in early childhood policy and programming, has been previously noted and critiqued largely due to the nature of the evidence base on which the argument is presented (Nsamenang 2006; Penn 2011; Woodhead 2006). While the importance of framing ECCE policy within sound scientific evidence is widely acknowledged and espoused (Rebello Britto et al. 2008), the country presentations represented in Dataset Two indicate that this discourse could now be usefully combined with more contextually focused knowledge/'evidence' on the particular needs and challenges associated with ensuring that ECCE provision does, indeed, result in long-term, positive outcomes.

\section{Theme Two: emphasis on funding/financing of ECCE}

Across Dataset One, regardless of the particular Forum theme within which presentations/papers were discussed, consistent reference was also made to aspects of financing ECCE policy and programming, primarily in terms either the importance of investing in ECCE, or in terms of the importance of ensuring that funding results in effective outcomes/returns. These messages are consistent with those that characterize Theme One, outlined above, which seems to 'make the case' for investment in ECCE, while this theme reflects a concern with compelling governments to invest more. Excerpts presented here, organized into two sub-themes, illustrate the nature of these messages:

Strong economic returns on ECCE investment (for future humanity) 'Investment in young children must be a cornerstone of all development agenda and policies'

'We need to accelerate the investment process'

'investing in early childhood education and care policies will ensure long-term national growth and competitiveness'

'investment in ECCE at the national level is an urgent imperative'

'Early childhood is the most effective and cost-efficient time to ensure that children can benefit from school and later opportunities'

'It is therefore essential to invest more and better in ECCE' 
'Long-term effects on schooling and income contribute to continued inequities in the next generation'

Linking financial allocation with policy effectiveness '..importance of policy design that delivers clear and tangible results in the context of economic development'

'setting specific, measurable and achievable goals and undertaking consistent monitoring and evaluation on key performance indicators'

'Immediate impact should be at least twice the size of desired long-term impact'

'Begin with a proven model'

'policies that will deliver'

'Invest in research that monitors and evaluates programmes to identify most effective interventions'

Lack of government financing of ECCE is commonly discussed as a major impediment to policy implementation, sometimes in international reports with specific reference to countries in the Asia Pacific region (Rebello Britto et al. 2013b). Indeed, several regional reports on ECCE in Asia and the Pacific have noted the lack of financial support, at national level, for implementation of ECCE policies (Pearson and Tan 2013; Rao and Jin 2010; UNESCO/ UNICEF 2012). In response, the economic argument for investing in ECCE, which points to cost-saving benefits to wider society of providing healthy foundations for young children (Heckman 2006) has gained traction in the field of ECCE during recent years.

Increasingly, as ECCE has become more established within the region, there is also acknowledgement that effective policies require not only financing but clear goals that are responsive to well-defined needs and priorities. This is arguably reflected in the subtheme of Linking financial allocation with policy effectiveness, and the information provided by individual countries, documented in analyses of Dataset Two provides valuable direction in terms of beginning to clearly identify such priorities at the national level.

\section{Theme Three: repetition of key agendas/goals}

The messages that combine to constitute this third theme can be seen to reflect particularly closely a primary agenda of the Forum, as outlined in the Forum concept note, and mentioned earlier in the paper: '....an urgent need to accelerate the region's quantitative and qualitative progress toward EFA Goal 1 and to renew the countries' commitment to inclusive and holistic development and learning of children' (UNESCO 2013, p. 6). This theme contains three key sub-themes, including one that reflects a focus on urgency of responding to EFA goals through investment in ECCE, a second that contains messages related to the importance of equity, quality and capacity building (all key priorities for international donor agencies, UNESCO 2013), and a third that reflects a recent shift towards calls for greater knowledge sharing and collaboration across the region (Pearson and Tan 2013). The following excerpts from Dataset One illustrate the nature of these key messages:

Increased public investment in ECCE-urgency 'pace of progress has stagnated in recent years, and is insufficient to ensure that, by 2015, all girls and boys complete a full course of primary schooling' 
'we have been engaged in discussions on how to secure ECCE budget'

'to close these gaps as soon as possible'

'momentum being built up by the Education for All Progress assessment towards 2015 needs to be used as an opportunity to increase the visibility of ECCE'

Equity in provision; high quality; capacity building; policy/program development 'Asia-Pacific countries must continue to develop the capacity of the ECCE system'

'Increased political awareness but further need for awareness raising among parents and communities'

'Invest in the most disadvantaged'

'Ensure that rapid expansion in access to services in the Asia Pacific region is not associated with a decrease in their quality'

'Access to high quality ECCE remains limited and highly unequal across and within nations'

Collaboration and knowledge dissemination 'As such collective interest and support... I hope this forum, by functioning as a platform to share and collaborate.'

'platform where we will be sharing ideas and views..'

'..we should continue the sharing, exchanging and co-operating with other partners'

It is important to note that the purpose of this policy forum is made overt in the concept note, as explained earlier in the "Methods". The presence of key messages signaling particular agendas is, therefore, not unexpected, neither is the nature of this agenda, which makes repeated calls for greater commitment to, and investment in, ECCE, as part of progress towards meeting quantitative EFA commitments. What is worthy of note here is the extent to which achieving external targets is highlighted as key to enhancing ECCE policy and programming in this context. Once again, information contained in Dataset Two provides a strong basis for moving towards agendas and goals that not only reflect international development goals and agendas, but also are responsive to the unique contexts and circumstances of children that they are intended to support. For example, within this broad theme, a particular sub-focus on collaboration and knowledge sharing was found. Similar messages related to the importance of collaboration and mutual support across organisations and countries were identified within Dataset Two (assumed to reflect national interests). That this aspect of policy and program delivery is referred to by both sets of data (at the international/regional level and at the national level) is important in terms of highlighting that there are possibilities for greater harmonization and coherence between international, regional and national goals and priorities in policy making.

\section{Dataset Two: national priorities}

Dataset Two, consisting of notes from fifteen country presentations in powerpoint form, was analyzed separately from Dataset One, using the same procedures/steps, involving a process of familiarization with the data, noting repeated terms, emergent themes, and returning to the complete dataset for review and confirmation of key themes. It is important to note a subtle, but significant, difference in the nature of information 
provided between the two datasets. Whereas the information provided in Dataset One seemed to reflect a concern with advocacy, the presentation of 'scientific evidence' and 'best practice', Dataset Two was characterized more by the presentation of factual information about the current status of ECCE within individual countries. This is reflected in the way in which information related to each theme is presented here, with extracts from Dataset Two consisting more of factual pieces of information from individual countries that constitute the theme and sub-themes. Three distinct themes (Evidence of Diversity; Importance of Engagement Across Stakeholder Groups and Gaps and Challenges) characterized the complete Dataset.

\section{Theme One: evidence of diversity}

The first theme to be quite clearly identifiable within Dataset One was the extent of diversity that exists across the 15 countries, with a wide range of implications for policy making and programming. As preparation for the forum, countries were sent a set of guidelines for reporting. Although the presentations differed in nature and format, each began with one or more slides on context setting, highlighting the considerable diversity that is found within the Asia Pacific region. Five sub-themes emerged within this first theme, highlighting various aspects of difference in ECCE contexts across the countries, as presented below. Specific examples from countries are included, to highlight key points within each sub-theme.

Populations The most striking differences between countries are reflected in population size, which ranges from very small total population sizes (733,000 in Bhutan and a population of 165,000 children in Hong Kong SAR, $100 \%$ of whom are enrolled in kindergarten) to the immense, 160 million strong population of India, where there are reportedly 15 million plus children in the 0 to 6-year age range.

In most countries, the current child and youth population is recorded as significant (as high as $42 \%$ of total in Bhutan for example).

People and place Another key area of diversity reflected in the reports relates to both people and place. Whereas one or two countries describe relatively homogeneous societies with dominant mainstream cultures (i.e., Hong Kong SAR), others report considerable ethnic and geographical diversity (the Philippines, for example, reports 160 indigenous groups, speaking 175 languages and living in communities spread across 7000 islands).

History of formalized EC(E) A third aspect of diversity that emerges from the 15 presentations is the extent to which the historical background of formalized care and education for young children differs across countries. Some countries in the Asia Pacific region are revising or reconstructing policies on the basis of a long history of provision (Japan, for example, where kindergartens were established in the late 1800s, and more recently Bangladesh, where 'baby classes' have existed since 1970s). For others, however, formalized provision of ECCE is a much more recent concept (Bhutan, for example, where the focus on formalized ECCE has been in place since 2000 as part of formal education policy and only since 2009 as a 'separate entity'). 
There is diversity not only in terms of length, but also in terms of adjustment following political change. In the Central Asia republics (the Kyrgyz Republic), for example, rapid reductions in provision of formalized ECE were experienced in the early 1990s, following independence. Both the Kyrgyz Republic and Uzbekistan now report recent re-growth and a strengthening policy focus on ECCE.

Approach to EC A fourth and important aspect of diversity exists in terms of differences in the nature and implementation of 'early childhood care and education'. In some countries, a relatively exclusive focus on 'ECE-early childhood education' and preparing children for formal education/schooling appears to exist (nb. this pattern seems unaffected by the fact that some countries presented reports as part of the forum's 'transition to school' sub-theme). Hong Kong SAR, the Kyrgyz Republic, Mongolia and Uzbekistan appear to be largely oriented towards the provision of preschooling, for example. Other countries, however, indicate a strong concern with 'ECD-early child development,' involving greater emphasis on informal care, parent and community participation, and the provision of integrated health, early stimulation and early learning services (i.e., India and Sri Lanka), while others indicate an interest in/focus on a combination of both (i.e., Nepal).

Mixed modes of funding are also reflected in the 15 country presentations, ranging from policy contexts in which the role of government is largely as regulator and subsidizer of privately operated early learning and care (for example, Hong Kong and New Zealand) to situations in which the government is sole provider, supported only in technical terms by NGO's (Mongolia).

Definitions Related to the fourth sub-theme, a final sub-theme reflects distinctions in terminology used by individual countries to refer to 'ECCE' policy and programming:

ECD (Bangladesh, Mongolia); ECCD (Bhutan, The Philippines, Sri Lanka); PPE (Preprimary Education-HK); ECCE (India, Japan); Preschool education (Kyrgyz republic, Uzbekistan); ECE (NZ, Vietnam); ECCE (Thailand, Vanuatu); mixed use of terminology (Nepal). As outlined briefly in the description of sub-theme four, the terminology used by each country may reflect policy contexts, with ECE (early childhood education) being supported by Ministries of Education, and ECD (early childhood development), ECCE (early childhood care and education) and ECCD (early childhood care and development)reflecting a more holistic policy approach involving multiple stakeholders.

\section{Theme Two: importance of engagement across stakeholder groups}

A second key theme contained in Dataset Two was repeated mention across country reports of the existence of, or need for, engagement across stakeholder groups. As indicated in the "Background" of this paper, provisioning for the care and education of young children necessarily involves a level of engagement with parents, communities, professionals and non-government bodies, as well as policy making and funding departments. This concern is reflected in the country reports, in which four key sub areas of potential engagement were identified: 
EC networks Several countries described the existence of, or need for, increased (formal) cooperation/collaboration across stakeholder groups. In some countries, early childhood networks have already been established, with involvement of representatives from NGOs; research and training institutes, and ministries (i.e., Bangladesh, India, The Philippines, Nepal, Sri Lanka). The Philippines report refers to this level of convergence as 'best practice'.

Focus on inter-ministerial commitment A broad level of concern with promoting commitment and collaboration across government departments (both vertical-across key ministries, and horizontal-between national, regional and local government units) was expressed across country presentations. Larger countries in particular (India, the Philippines, Sri Lanka) refer to the importance of collaboration and 'synchronicity' across departments involved in provision of ECCE. Other countries refer to the importance of convergence across health/welfare and education sectors for an integrated approach to ECCE (Japan, Nepal, Sri Lanka).

Community awareness/involvement A third recurrent set of messages within the theme of engagement highlights the importance specifically of promoting community and parent participation (Bhutan, Japan, India, NZ, Sri Lanka, Thailand, Vanuatu), either through awareness raising or promoting active participation in provision of ECCE supports.

\section{Theme Three: gaps and challenges}

The third key theme to emerge from country presentations involves gaps, or areas of concern, shared across the presentations. Once again, it is important to note that the presence of this theme is not surprising, as countries were encouraged in the forum preparation guidelines for country reports, to outline continuing gaps and/or challenges in provision of ECCE. Worthy of attention, however, is the nature of challenges that are reported by the fifteen countries, and the extent to which they provide greater, more persuasive substance to the focus on gaps in investment that emerged from Dataset One. Excerpts to illustrate this overarching theme are organized around four sub-themes, reflecting gaps that were consistently reported in country presentations:

Education; training; awareness raising; capacity building Most countries highlighted the need for enhanced education and training for ECE practitioners/teachers. Noted also was the importance of raising awareness and knowledge of ECCE among district officers and education officers (Bhutan, Bangladesh, Vietnam).

Many countries also specifically referred to the importance of awareness raising in communities, referring to the need for nation-wide efforts in advocacy; raising awareness about ECE and encouraging community involvement (i.e., particularly Sri Lanka).

Information: data; evidence; standards; monitoring frameworks Most countries also referred to the need for more data 'evidence', although the nature of preferred evidence was not detailed. The Philippines called specifically for a 'realistic review', supporting the argument that many countries are now ready to 'stock take' on current policies and programmes, to assess examples of both effective and redundant approaches. Some 
countries called specifically for greater knowledge sharing (Bhutan), while others pointed specifically to the need for continued NGO support (Bangladesh), in the form of developing innovative models for ECCE provision (Uzbekistan), and financial support (Nepal).

Linkage/coherency between state, district and local government units Gaps in priority setting and synchronicity across departments were reported (Sri Lanka), as well as the need for capacity building at local level to implement policy (Bangladesh). India mentioned the need for MoUs between state and LGUs (Local Government Units), and gaps in government coverage were also reported (Kyrgyz republic).

Formalization of EC networks/inter-ministerial commitment While several countries (Bangladesh, India, Nepal, the Philippines) have established national and regional networks bringing together stakeholders, and others have increased inter-ministerial commitment, via shared funding arrangements, etc., many call for stronger institutionalization/formalization of these networks (i.e., Nepal).

\section{Conclusions: finding ways to move forward}

Limitations to the findings and conclusions presented here are highlighted throughout the paper. The country reports used as a basis for these analyses cannot be seen to reflect the complete policy context in each of the 15 countries included; rather, they provide brief insight into policy concerns for countries in which ECCE programmes are currently being implemented. Limitations and idiosyncrasies in the methodology related to the nature of the dataset used for analysis have also been referred to throughout the paper, particularly in the "Methods" section. Despite these limitations, the analyses may be seen to provide useful points for consideration and further discussion. As a starting point, they indicate that further work along these lines is needed, and would be strengthened by a more comprehensive, systematic and participant-focused approach, involving policy makers and country-based professionals/experts in discussion around possibilities for strengthening coherence between international and national goals.

The purpose of this analysis was, in response to current discussions around proposed shifts in international and national goal setting post-2015 (as outlined in the literature review), to (1) explore key themes in international/regional and country-level policyrelated priorities in ECCE, as expressed through two distinct sets of documents presented at the Asia Pacific Regional Policy Forum on ECCE, and (2) based on elements of similarity and difference between the themes identified within each dataset, to examine possibilities for greater balance and/or harmonization between 'international' and 'national' agendas and policy priorities for ECCE within the region.

The first finding of note is that the documents constituting Dataset Two provide a rich base of evidence that highlights the considerable variability and complexity of ECCE provision within the Asia Pacific region, both at the regional level and within national contexts. Relatedly, each country that was represented in these presentations was able to clearly articulate unique circumstances and concerns that could provide a basis for policy focus, providing evidence of both commonalities and distinctions in the status of ECCE and current concerns across countries within the region. Across all countries, a significant interest in building engagement and collaboration within and across nation 
was expressed. Equally, training, education and mentoring for ECCE professionals was referred to across a number of countries as a key contemporary challenge. Building on community capacities in supporting the provision of ECCE was also highlighted as a key need for most countries across the region, indicating a possible policy priority that would respond to unique localized circumstances. Distinctions were also clearly identifiable across countries. While the priority in providing formalized support for young children's care and education for some countries lies in ensuring that all children have access to center-based early learning opportunities, in other countries a greater need lies in ensuring that children's nutritional and health needs are met through community-based supports, while in others, an integrated approach is prioritized. Across both differences and similarities, the clear articulation of priorities, based on contextualized needs and issues, that is reflected in the themes found in Dataset Two, provides support for Harkness and Super's (2010) argument that effective policies are (or should be) grounded in and reflect unique contextual characteristics.

These findings provide support for the argument advanced by Koehler and colleagues (2012) that a shift in policy focus away from generic, global targets towards more localized issues (consisting of both concerns shared at regional level as well as those that are unique to individual countries) is timely. The sense of urgency, focus on financing and imperatives that is reflected in Dataset One reflects a concern (1) that policies have tended to reflect a preoccupation with achieving generic international targets in human development (Penn 2011; Waage et al. 2010) and (2) that there needs to be greater space for more localized and contextualized policy discussions (Koehler et al. 2012). The distinctive agendas outlined within the three themes identified in Dataset Two suggest that countries are in a position to contribute to such discussions, and that a constructive approach might be to balance these compelling global arguments against real, specific needs that have been identified by countries within the region.

As highlighted earlier, international developments in ECCE over the past decade have been heavily influenced by combined agendas outlined in the MDG framework (which is oriented towards quantitative global targets designed to eradicate poverty), and the Dakar Framework of Action, designed to support EFA. To date, the most explicit worldviews evident in ECCE, which have come to dominate global policy and practice through the kinds of agendas shaping meetings such as this Forum, are framed largely by generic, quantitative targets. While these targets have significantly contributed to the mobilization of commitment to important developmental goals that impact on ECCE, including universal enrolment in primary school, expanding access to early childhood education, and reduction of infant and maternal mortality, gaps are now being identified in terms of efforts to address critical sustainability issues such as effectiveness and relevance (Tawil 2013), in other words, 'quality'.

The insights contained in Dataset Two and analyzed here provide a basis from which to argue that the initial impetus provided by generic MDGs and EFA has resulted in, or supported, the establishment of unique, country-specific structures (or, at least, ideas) that can now be strengthened to assist countries in exploring innovative, localized methods by which they can really begin to protect and the needs and rights of young children, within the possibilities and confines of their own unique contexts. 
The themes identified in Dataset Two (Diversity, Engagement Across Stakeholder Groups; Gaps and Challenges) all strongly reflect a concern with how people and places shape ECCE in countries across the Asia Pacific region, as well as strong evidence that countries are in a position to determine policy goals that respond to local needs and priorities. Greater acknowledgment and promotion of these goals could assist in addressing the gaps related to effectiveness, relevance and sustainability that Tawil (2013) refers to. Support for this approach to goal setting is also reflected in (1) the Incheon Declaration, ratified by global leaders at the World Economic Forum in May 2015 (UNESCO 2015) and by proposals for the post-2015 era of human development goals globally. The United Nations Secretary General's synthesis report on the post-2015 sustainable development goals, The Road to Dignity by 2030 clearly highlights the importance, in advancing human development goals, of developing approaches and 'solutions' that are applicable and realistic across diverse countries and settings. As the synthesis report suggests, this will require more intense efforts to document and understand unique contexts:

People across the world are looking to the United Nations to rise to the challenge with a truly transformative agenda that is both universal and adaptable to the conditions of each country, and that places people and the planet at the center (UN 2014, p. 7).

For this shift in focus to occur, the goals and mandates which drive international donor agendas could be reframed to more effectively incorporate and reflect the diverse circumstances and needs of children that individual countries need to respond to in goal setting and policy making. The analyses presented here indicate that individual countries are able to clearly articulate (and, indeed, are responding to) the unique circumstances and priorities that shape formalized provision of ECCE. The role of international development organisations in supporting these efforts is crucial and invaluable, as acknowledged in the country presentations constituting Dataset Two. As we move towards 2015, efforts to promote greater harmonization in agendas between international organisations and individual countries in policy setting and implementation for ECCE, by advocating more nuanced agendas and goals based on localized needs and circumstances, may benefit work to enhance ECCE provision. Such efforts would (1) fit with and respond to broader current discussions that highlight a need for development goals to 'put people and place at the centre' and (2) enable better understanding of how organisations and individuals that function at international, national and local levels can work seamlessly together in achieving them.

\section{Abbreviations}

EFA: Education for All; MDG: millennium development goals; NGO: Non-government Organisation; LGU: Local Government Unit (The Philippines); ECCE: Early Childhood Care and Education; ECE: Early Childhood Education; ECD: Early Childhood Development; ECCD: Early Childhood Care and Development.

\section{Authors' information}

Emma Pearson is a Senior Lecturer in Education Studies, Faculty of Social Sciences, Bishop Grosseteste University. Her research (supported by consultancy work with UN agencies) is oriented towards deepening understandings about the important role of contexts in shaping young children's early learning and development experiences around the world. As part of her work in this area she has traveled throughout South East Asia and the Pacific islands.

\section{Acknowledgements}

This research received no specific grant from any funding agency in the public, commercial, or not-for-profit sectors. 
Received: 11 May 2015 Accepted: 25 November 2015

Published online: 21 December 2015

\section{References}

Braun, V., \& Clarke, V. (2006). Using thematic analysis in psychology. Qualitative research in Psychology, 3(2), 77-101.

Chartier, A.-M., Geneix, N. (2006). Pedagogical approaches to early childhood education. Background paper prepared for the EFA Global Monitoring Report 2007, Strong foundations: early childhood care and education. http://unesdoc. unesco.org/images/0014/001474/147448e.pdf.

Evans, J.L. (1995). Creating a shared vision: how policy affects early childhood care and development. Coordinators Notebook, 17, 1-19. http://www.ecdgroup.com/download/cc117aci.pdf.

Fukuda-Parr, S. (2012). Should global goal setting continue, and how, in the post-2015 era. United Nations Department of Economic and Social Affairs (DESA) Working Paper, (117). http://arab-tdp.org/system/USB/Reference\%20documents/ Other\%20publications/Should\%20global\%20goal\%20setting\%20continue-working\%20paper.pdf.

Fullan, M., \& Hargreaves, A. (1992). Teacher development and educational change. London: Falmer Press.

Hammersley, M. (2006). Sensitizing concepts. In V. Jupp (Ed.), The SAGE Dictionary of Social Research Methods. (pp. 280-281). London, England: SAGE Publications, Ltd. http://srmo.sagepub.com/view/the-sage-dictionary-of-socialresearch-methods/SAGE.xml.

Harkness, S., Super, C.M. (2010). Culture and policy in early childhood development. In R. E. Tremblay, M. Boivin, R. Peters (Eds), Encyclopedia on early childhood development [online]. Montreal: Centre of Excellence for Early Childhood Development and Strategic Knowledge Cluster on Early Child Development. http://www.child-encyclopedia.com/ documents/Harkness-SuperANGxp.pdf.

Heckman, J. (2006). Skill formation and the economics of investing in disadvantaged children. Science, 312, 1900-1902.

Kirk, J., \& Winthrop, R. (2006). Home-based schooling: access to quality education for Afghan girls. Journal of Education for International Development, 2(2), 1-9.

Koehler, G., Gasper, D., Jolly, R., Simane, M. (2012). Human security and the next generation of comprehensive human development goals. Institute for Development Studies: Sussex University. http://www.networkideas.org/alt/may2012/ Human_Security.pdf.

Lincoln, Y. S., \& Guba, E. G. (1985). Naturalist inquiry. Beverly Hills: Sage.

Myers, R. G. (2006). Quality in program of early childhood care and education (ECCE). Background paper prepared for the Education for All Global Monitoring Report 2007. Strong foundations: early childhood care and education. UNESCO. http://unesdoc.unesco.org/images/0014/001474/147473e.pdf.

Nsamenang, A. B. (2006). Cultures in early childhood care and education. Background paper for EFA Global Monitoring Report 2007. Strong foundations: early childhood care and education. http://unesdoc.unesco.org/ images/0014/001474/147442e.pdf.

Pearson, E., Tan, J. (2013). Fulfilling child rights through early childhood development. Background paper prepared for HLM on fulfilling child rights through ECD. UNICEF EAPRO. http://www.unicef.org/eapro/Working_paper_3_-_Early_ Childhood_Development.pdf.

Penn, H. (2011). Travelling policies and global buzzwords: how international non-governmental organizations and charities spread the word about early childhood in the global South. Childhood, 18(1), 94-113.

Rao, N., Jin, S. (2010). Early childhood care and education in the Asia Pacific region: moving towards goal 1: background report prepared for the world conference on early childhood care and education. Moscow, September 27-29. UNESCO. http://unesdoc.unesco.org/images/0018/001892/189210e.pdf\#xml=http://www.unesco.org/ulis/cgi-bin/ ulis.pl?database =\&set=4D015C24_0_374\&hits_rec=9\&hits_Ing=eng.

Rebello Britto, P., Cerezo, A., \& Ogbunugafor, C. B. (2008). How evidence can be used to inform policy: a case study of early childhood evidence-based policy development. International Journal of Early Childhood, 40(2), 101-118.

Rebello Britto, P., Engle, P. L., Super, C. M. (2013a). ECD: translating research to global policy. In P. R. Britto, P. L. Engle C. M. Super (Eds), Handbook of early childhood development research and its impact on global policy. (pp. 3-23). Oxford: Oxford University Press.

Rebello Britto, P., Yoshikawa, H., Van Ravens, J., Ponguta, L. A., Oh, S. S., Dimaya, R., Seder, R. C. (2013b). Understanding governance of early childhood development and education systems and services in low-income countries, Innocenti Working Paper No. 2013-07, UNICEF Office of Research, Florence.

Ryan, K. E., \& Cousins, J. B. (2009). The SAGE international handbook of educational evaluation. Los Angeles: SAGE.

Tawil, S. (2013). Coming full circle? Reflections on the International Education Agenda for 2015 and beyond. NORRAG NEWSbite (blog). http://norrag.wordpress.com/2013/03/20/ coming-full-circle-reflections-on-the-international-education-agenda-for-2015-and-beyond/.

UNESCO (2006). EFA global monitoring report 2007. Strong foundations: early childhood care and education. Paris: UNESCO. http://www.unesco.org/new/en/education/themes/leading-the-international-agenda/efareport/ reports/2007-early-childhood/.

UNESCO (2013). Asia Pacific regional policy forum on early childhood care and education: Final Report. http://www. unescobkk.org/fileadmin/user_upload/appeal/ECCE/ECCE_Forum_2013/Asia-Pacific_Regional_Policy_Forum_ENGLISH_REVISED_e-pub_final.pdf.

UNESCO (2015). Incheon declaration: equitable and inclusive quality education and lifelong learning for all by 2030: transforming lives through education. https://en.unesco.org/world-education-forum-2015/incheon-declaration.

UNESCO/UNICEF (2012). Asia-Pacific end of decade notes in education for All: goal 1 early childhood care and education. http://www.unicef.org/rosa/217145e.pdf.

United Nations (2014). The Road to Dignity by 2030: ending poverty, transforming all lives and protecting the planet: synthesis report of the Secretary-General on the post-2015 agenda (advance unedited version, released 4 December). http://www.un.org/disabilities/documents/reports/SG_Synthesis_Report_Road_to_Dignity_by_2030.pdf. 
Vergara del Solar, A. (2014). Public policy discourses on childhood during Chilean post-authoritarian democracy: a case of discursive colonization by the language of free market. Childhood,. doi:10.1177/0907568214549079.

Waage, J., Banerji, R., Campbell, O., Chirwa, E., Collender, G., Dieltiens, V., \& Unterhalter, E. (2010). The millennium development goals: a cross-sectoral analysis and principles for goal setting after 2015: Lancet and London International Development Centre Commission. The Lancet, 376(9745), 991-1023.

Woodhead, M. (1999). Towards a global paradigm for research into early childhood education. European Early Childhood Education Research Journal, 7(1), 5-22.

Woodhead, M. (2006). Changing perspectives on early childhood: theory, research and policy. Paris: UNESCO. http://unesdoc. unesco.org/images/0014/001474/147499e.pdf.

Submit your manuscript to a SpringerOpen ${ }^{\circ}$ journal and benefit from:

- Convenient online submission

- Rigorous peer review

- Immediate publication on acceptance

- Open access: articles freely available online

- High visibility within the field

- Retaining the copyright to your article

Submit your next manuscript at $\mathbf{s p r i n g e r o p e n . c o m ~}$ 